\title{
Comments on "Solubility and Dissolution Thermodynamic Data of Cefpiramide in Pure Solvents and Binary Solvents"
}

\author{
William E. Acree Jr. ${ }^{1}$
}

Published online: 24 January 2018

(C) Springer Science+Business Media, LLC, part of Springer Nature 2018

\begin{abstract}
Errors are found in the mathematical correlation based on the combined Jouyban-Acree and Modified Apelblat models for describing the variation in the mole fraction solubility of cefpiramide with temperature and solvent composition for the binary aqueous-ethanol solvent system. The equation coefficients given by Tang and coworkers, when substituted into the model equation, do not yield the authors' calculated mole fraction solubilities of cefpiramide.
\end{abstract}

Keywords Cefpiramide solubility - Binary aqueous-ethanol solvent mixtures - Binary aqueous-2-propanol solvent mixtures · Mathematical representation of solubility data in binary solvent mixtures

In a recent paper appearing in This Journal Tang and coworkers [1] reported the solubility of cefpiramide in five neat mono-solvents (water, ethanol, 1-propanol, 1-butanol and 2propanol) and in two binary aqueous-organic solvent mixtures. The two organic solvents are ethanol and 2-propanol. Solubilities were measured at six temperatures from 278.2 to 303.2 K using a spectroscopic method of chemical analysis. The authors used the combined Jouyban-Acree and Modified Apelblat models:

$$
\begin{aligned}
\ln \left(x_{\mathrm{A}}\right)_{m, T}= & A_{1}+\frac{A_{2}}{T}+A_{3} \ln T+A_{4} x_{\mathrm{B}}^{0}+A_{5} \frac{x_{\mathrm{B}}^{0}}{T}+A_{6} \frac{\left(x_{\mathrm{B}}^{0}\right)^{2}}{T}+A_{7} \frac{\left(x_{\mathrm{B}}^{0}\right)^{3}}{T}+A_{8} \frac{\left(x_{\mathrm{B}}^{0}\right)^{4}}{T} \\
& +A_{9} x_{\mathrm{B}}^{0} \ln T
\end{aligned}
$$

to describe how the measured mole fraction solubility of cefpiramide, $\left(x_{\mathrm{A}}\right)_{m, T}$, varied with both temperature, $T$, and initial mole fraction composition of the binary solvent mixture,

This comment refers to the article available at https://doi.org/10.1007/s10953-017-0664-1.

William E. Acree Jr.

acree@unt.edu

1 Department of Chemistry, University of North Texas, 1155 Union Circle Drive \#305070, Denton, TX 76203, USA 
$x_{\mathrm{B}}^{0}$. The curve-fit equation coefficients, $A_{i}$, were determined by regressing the experimental mole fraction solubility data in accordance with Eq. 1 . The authors tabulated the calculated curve-fit equation coefficients in Table 8 of their published paper [1]. Only the statistically significant coefficients were tabulated. The authors stated in the manuscript that Eqs. 2 and 3 below (Eqs. 15 and 16 in the published paper):

$$
\begin{gathered}
\ln \left(x_{\mathrm{A}}\right)_{m, T}=A_{1}+A_{3} x_{\mathrm{B}}^{0}+A_{5} \frac{\left(x_{\mathrm{B}}^{0}\right)^{2}}{T}+A_{7} \frac{\left(x_{\mathrm{B}}^{0}\right)^{3}}{T}+A_{8} \frac{\left(x_{\mathrm{B}}^{0}\right)^{4}}{T} \\
\ln \left(x_{\mathrm{A}}\right)_{m, T}=A_{1}+A_{3} x_{\mathrm{B}}^{0}+A_{5} \frac{x_{\mathrm{B}}^{0}}{T}+A_{6} \frac{\left(x_{\mathrm{B}}^{0}\right)^{2}}{T}+A_{7} \frac{\left(x_{\mathrm{B}}^{0}\right)^{3}}{T}+A_{8} \frac{\left(x_{\mathrm{B}}^{0}\right)^{4}}{T}+A_{9} x_{\mathrm{B}}^{0} \ln T
\end{gathered}
$$

were the final equations for predicting the solubility of cefpiramide in binary aqueousethanol and aqueous-2-propanol solvent mixtures in the solvent mole fraction composition range from $x_{\mathrm{B}}^{0}=0.0$ to $x_{\mathrm{B}}^{0}=0.9$, respectively.

The purpose of this commentary is to alert journal readers to several errors in the authors' mathematical correlations. Careful examination of Eqs. 1-3 reveals that the curve-fit equation coefficients are identified differently in Eq. 1 than in Eqs. 2 and 3. The $A_{3}$ equation coefficient in Eq. 1 corresponds to the coefficient in the $A_{3} \ln T$ term, whereas in Eqs. 2 and 3 the $A_{3}$ coefficient corresponds to the $A_{3} x_{\mathrm{B}}^{0}$ term. There is a similar problem with the $A_{5}$ coefficient in Eqs. 1 and 2. The change in symbolism can lead to confusion when it comes to substituting the numerical values for the equation coefficients. For example, in Table 7 of the published paper [1] the authors gave numerical values of $A_{1}=-93.252, A_{3}=13.927, A_{5}=3559.445, A_{7}=10448.710$ and $A_{8}=8314.726$ as the coefficients for binary aqueous-ethanol solvent mixture. Does one substitute the numerical values into Eq. 1 to give:

$$
\ln \left(x_{A}\right)_{m, T}=-93.252+13.927 \ln T+3559.445 \frac{x_{\mathrm{B}}^{0}}{T}+10448.710 \frac{\left(x_{\mathrm{B}}^{0}\right)^{3}}{T}+8314.726 \frac{\left(x_{\mathrm{B}}^{0}\right)^{4}}{T}
$$

or does one substitute the numerical values into Eq. 2 to yield:

$$
\ln \left(x_{A}\right)_{m, T}=-93.252+13.927 x_{\mathrm{B}}^{0}+3559.445 \frac{\left(x_{\mathrm{B}}^{0}\right)^{2}}{T}+10448.710 \frac{\left(x_{\mathrm{B}}^{0}\right)^{3}}{T}+8314.726 \frac{\left(x_{\mathrm{B}}^{0}\right)^{4}}{T}
$$

What I have done is to calculate the solubility of cefpiramide for the binary aqueousethanol solvent system at $T=298.2 \mathrm{~K}$ using both Eqs. 4 and 5 . The results of my calculations are summarized in the third and fourth columns of Table 1 of this commentary, along with the calculated values that the authors gave in Table 1 of their published paper for water and for the five binary solvent compositions studied. According to the headings in Table 3 of the published paper [1], the authors' calculated values are presumably based on Eq. 5 (which would be Eq. 15 in the published paper with the coefficients inserted). Careful examination of the numerical entries in the last three columns of Table 1 reveals that neither Eq. 4 nor Eq. 5 reproduce the authors' calculated values. In the case of Eq. 5 the calculated mole fraction solubility of cefpiramide would be the same at all six temperatures for $x_{\mathrm{B}}^{0}=0.0$ as only the first term would contribute to the calculation. The remaining four terms would equal zero at $x_{\mathrm{B}}^{0}=0.0$. Equation 4 on the other hand gives a 
Table 1 Comparison between the experimental mole fraction solubilities of cifpiramide, $\left(x_{\mathrm{A}}\right)_{m, T}$, calculated values reported by Tang and coworkers [1], and calculated values based on Eqs. 4 and 5

\begin{tabular}{lllll}
\hline$x_{B}^{o}$ & $10^{6} \times\left(x_{\mathrm{A}}\right)_{m, T}^{\exp }$ & $10^{6} \times\left(x_{\mathrm{A}}\right)_{m, T}^{\text {calc,eq.4 }}$ & $10^{6} \times\left(x_{\mathrm{A}}\right)_{m, T}^{\text {calc,eq.5 }}$ & $10^{6} \times\left(x_{\mathrm{A}}\right)_{m, T}^{\text {calc,authors }}$ \\
\hline 0.0000 & 0.8495 & 0.9197 & $3.171 \times 10^{-35}$ & 0.9175 \\
0.1007 & 2.873 & 3.180 & $1.512 \times 10^{-34}$ & 2.952 \\
0.2010 & 9.941 & 14.09 & $1.174 \times 10^{-33}$ & 7.957 \\
0.4008 & 20.83 & 2156 & $1.123 \times 10^{-30}$ & 23.61 \\
0.6010 & 21.44 & $9.172 \times 10^{7}$ & $7.798 \times 10^{-25}$ & 22.63 \\
0.8011 & 19.92 & $8.459 \times 10^{16}$ & $3.050 \times 10^{-14}$ & 19.03 \\
0.8994 & 29.65 & $4.180 \times 10^{23}$ & $1.348 \times 10^{-6}$ & 30.03 \\
\hline
\end{tabular}

calculated value of $10^{6} \times\left(x_{\mathrm{A}}\right)_{m, T}^{\text {calc }}$ close to the value reported by the authors for $x_{\mathrm{B}}^{0}=0.0$; however, calculated values at the larger mole fractions of solvent component B exceed unity. Mole fraction compositions cannot exceed unity. There are clearly problems with the $A_{i}$ equation coefficients given in the paper by Tang and coworkers [1] for the aqueousethanol solvent system. I suspect that one of the authors' tabulated equation coefficients (perhaps the $A_{7}$ coefficient) is missing a negative sign.

There is also an error in the symbolism associated with the equation coefficients for the binary aqueous-2-propanol solvent mixture reported in reference 1 . The numerical value for the $A_{3}$ coefficient should pertain to the $A_{3} \ln T$ term, and not the $A_{3} x_{\mathrm{B}}^{0}$ term as implied by Eq. 16 in the authors' published paper [1]. If the $A_{3}$ coefficient were to apply to the $A_{3} x_{\mathrm{B}}^{0}$ term then the calculation would yield $\ln \left(x_{\mathrm{A}}\right)_{m, T}=-89.733$ at $x_{\mathrm{B}}^{0}=0.0$, which would correspond to an aqueous mole fraction solubility of $\left(x_{\mathrm{A}}\right)_{m, T}=1.07 \times 10^{-39}$ for all six temperatures studied. The authors' calculated value for $T=298.2 \mathrm{~K}$ is much larger, e.g., $10^{6} \times\left(x_{\mathrm{A}}\right)_{m, T}^{\text {calc,authors }}=0.9568$. As an informational note, the authors' tabulated coefficients (using $A_{3}$ for the $A_{3} \ln T$ term) for the binary aqueous-2-propanol system are much better at reproducing the calculated mole fraction solubilities at $T=298.2 \mathrm{~K}$ reported in Table 4 of the published paper. I only checked only the calculations for $T=298.2 \mathrm{~K}$.

\section{Reference}

1. Tang, F., Wu, S., Zhao, S.: Solubility and dissolution thermodynamic data of cefpiramide in pure solvents and binary solvents. J. Solution Chem. 46, 1556-1574 (2017) 